Article

\title{
FT-IR Examination of the Development of Secondary Cell Wall in Cotton Fibers ${ }^{\dagger}$
}

\section{Michael Santiago Cintrón ${ }^{1, *}$ and Doug J. Hinchliffe ${ }^{2}$}

1 Cotton Structure \& Quality Research Unit, Southern Regional Research Center (SRRC), ARS, USDA, New Orleans, LA 70124, USA

2 Cotton Chemistry \& Utilization Research Unit, Southern Regional Research Center (SRRC), ARS, USDA, New Orleans, LA 70124, USA; E-Mail: doug.hinchliffe@ars.usda.gov

$\dagger$ Mention of a product does not constitute a warranty by the U.S. Department of Agriculture and does not imply its approval to the exclusion of other products that may also be suitable.

* Author to whom correspondence should be addressed; E-Mail: michael.santigo@ars.usda.gov; Tel.: +1-504-286-4276; Fax: +1-504-286-4217.

Academic Editor: Noureddine Abidi

Received: 16 September 2014 / Accepted: 27 January 2015 / Published: 29 January 2015

\begin{abstract}
The secondary cell wall development of cotton fibers harvested at 18, 20, 24, 28, 32, 36 and 40 days after flowering was examined using attenuated total reflection Fourier transform-infrared (ATR FT-IR) spectroscopy. Spectra of deuterated cotton fibers did not demonstrate significant changes in their $\mathrm{O}-\mathrm{H}$ stretching band shapes or positions during development. Only a progressive increase in $\mathrm{O}-\mathrm{H}$ band intensity was observed. Results indicate that the highly crystalline cellulose component produced during secondary cell wall formation maintains the hydrogen bonding network observed for the primary cell wall. Other general changes were observed for the regular ATR spectra. A progressive intensity increase for bands assigned to cellulose $\mathrm{I}_{\beta}$ was observed during fiber development, including a marked intensity increase for vibrations at 1002 and $985 \mathrm{~cm}^{-1}$. In contrast, $\mathrm{C}-\mathrm{O}$ vibrational bands from dominant conformations observed at 1104, 1052, $1028 \mathrm{~cm}^{-1}$ undergo a modest intensity increase during secondary cell wall development.
\end{abstract}

Keywords: cotton; FT-IR; moisture; maturity; cell wall 


\section{Introduction}

Cotton fibers are exceedingly long cells that grow from the epidermal cells of the cotton seed [1]. When fully mature, these linear appendages are mostly composed of cellulose, but they also contain small amounts of cellular proteins, pectic materials, waxes, sugars, organic acids and trace amounts of other chemical compounds [2,3]. Due to their length, ease of growth, and relative structural and biological simplicity, cotton fibers are particularly suitable for examining changes that occur during plant cell wall development.

The cotton fiber undergoes four stages of development: initiation, elongation, secondary cell wall (SCW) biosynthesis, and maturation [1,4,5]. During fiber initiation, which begins prior to the day of anthesis (DOA), a portion of ovule epidermal cells differentiate into fiber cells [1]. Cell elongation quickly follows and allows for the formation of an elongated primary cell wall and a waxy surface cuticle. Cotton fibers reach their final lengths around 21-35 days post-anthesis (DPA), depending on the genetic line and growing conditions [1,4]. During secondary cell wall production, additional cellulose is deposited in layers along the inner limits of the primary cell wall, significantly increasing the fiber wall thickness until the SCW is $2-6 \mu \mathrm{m}$, usually between 30 and 45 DPA. Since the mature cotton is composed of $>95 \%$ cellulose, proper cellulose deposition in this stage is vital for obtaining cotton fiber with commercially desirable properties like low micronaire and high fiber strength. When mature, the boll of cotton opens and the fibers becomes exposed to ambient conditions and quickly dry.

Molecular biology and gravimetric tools have been extensively employed in the examination of cellulose cell wall development in cotton and other plant cells [5,6]. However, gravimetric methods that examine changes in fiber composition (i.e., pectin, cellulose and lignin content) can consume significant amounts of sample, which complicates their use in fiber development studies [7,8]. More recent efforts have used Fourier transform-infrared (FT-IR) techniques to explore cell walls and their development in cotton fibers. FT-IR techniques are rapid, reproducible and need not consume fiber samples. Abidi and coworker utilized attenuated total reflection (ATR) FT-IR spectroscopy in tandem with thermo gravimetric analysis (TGA) to describe vibrational changes in the spectra of cotton fibers harvested at different DPA [9,10]. The disappearance of vibrations arising from non-cellulosic components allowed them to observe the transition from primary to secondary wall development. Changes in the vibrational spectra of maturing cotton fibers can also be used to predict commercially relevant cotton quality measurements. Liu and his coworkers used the difference in the $\mathrm{C}-\mathrm{O}$ stretches of immature and mature fibers to develop a rapid method for estimating cotton fiber maturity [11]. While Abidi and his coworkers used Partial Least Square regressions to estimate cotton fiber micronaire and fiber surface area [12].

Previous reports have described changes in IR spectra of cotton fibers harvested at different days after flower blooming $[9,10,13]$. Given that moisture is well known to affect cotton fiber properties, we were interested in gaining a better understanding of reported changes of IR bands that can serve as markers of moisture interaction, like the fiber $\mathrm{O}-\mathrm{H}$ stretching and absorbed water bands. Towards this end, experiments with $\mathrm{D}_{2} \mathrm{O}$-exchanged cotton fibers were performed, since deuteration decreases the contributions of readily accessible O-H groups [14]. Notably, recent cell wall development studies have not included exchange studies $[9,10]$. The vibrational spectra of cotton fibers harvested between 18 and 40 DPA were examined, a time period during which formation of the secondary cell wall 
occurs $[1,15]$. Changes in the regular and $\mathrm{D}_{2} \mathrm{O}$-exchanged spectra are highlighted. Band assignments reflect reports of highly crystalline cellulose $I_{\beta}[16]$, the predominant component of cellulose in higher plants.

\section{Experimental Section}

\subsection{Plant Material and Field Collection}

The examined germplasm line, MD 90ne, was grown in 2009 under standard field conditions in New Orleans, LA. The development and release of the germplasm line MD 90ne, including fiber quality data and fiber developmental studies, were previously described $[15,17,18]$. Cotton samples at different developmental stages were obtained by first tagging cotton flowers on DOA, and then harvesting fibers at 18, 20,24, 28, 32, 36 and 40 days post-anthesis (DPA). These time periods were chosen since they coincide with secondary cell wall development $[1,15]$. Beginning with the 20 DPA time points, samples were harvested every 4 days in order to maximize the collected sample sizes. Three biological replications were obtained at each developmental point. Fibers were separated from the cotton seed by hand and allowed to dry at room temperature. Prior to fiber tests, fiber samples were allowed to equilibrate in a conditioning room set at $70 \pm 2{ }^{\circ} \mathrm{F}$ and $65 \% \pm 2 \%$ relative humidity (RH) for at least $24 \mathrm{~h}$.

\subsection{FT-IR Analysis}

Cotton fibers from each developmental stage were examined with FT-IR spectroscopy. All spectra were collected on a Vertex 70 (Bruker Optics, Billerica, MA, USA) equipped with a mid-IR ceramic source, a KBR beam splitter, a deuterated triglycine sulfate detector, and an ATR sampling accessory (Pike Technologies, Madison, WI, USA) with a diamond-ZnSe reflective crystal. Prior to measurements, sample and instrument compartments in the Vertex 70 were flushed with a stream of high-purity $\mathrm{N}_{2}(\sim 30 \mathrm{~min})$ to reduce water vapor and $\mathrm{CO}_{2}$ features in the collected spectra. A positive pressure of $\mathrm{N}_{2}$ was maintained during measurements. Cotton samples ( $\left.\sim 200 \mathrm{mg}\right)$ were combed, placed on top of the ATR crystal and secured with a metal clamp in a manner that assured consistent pressure for all samples. Three measurements at three different sample locations were performed for each cotton sample. A total of 256 scans were measured for each sample point with a resolution of $4 \mathrm{~cm}^{-1}$ (3800-600 $\left.\mathrm{cm}^{-1}\right)$, and the resulting spectra were corrected against an air background. Spectral manipulation was kept to a minimum. Spectra for each sample were averaged, baseline-corrected and normalized using the OPUS spectroscopy software (version 6.5; Bruker Optics, Billerica, MA, USA). Spectra are presented without ATR correction or atmospheric compensation. Resulting spectra were exported to Microsoft Excel and plotted with IGOR Pro (version 6.2; Wavemetrics, Lake Oswego, OR, USA). Spectra are shown without an absorbance scale and most are shifted along the intensity axis. First derivative spectra were obtained using standard algorithms included in the OPUS software.

\subsection{Cotton Fiber Deuteration}

Sub-samples from fibers harvested at 18, 24 and 40 DPA were allowed to exchange in a globe box maintained at 30\% Relative Humidity (RH) for at least $24 \mathrm{~h}$. Fibers were then placed in a small beaker which was in turn placed inside a mason jar. The bottom of the mason jar was filled with deuterated 
water (Acros Organics, Geel, Belgium), and the mason jar closed so as to allow deuterated water vapors to exchange with the sample. After exchanging for $24 \mathrm{~h}$, fibers were essentially wet. Excess water was removed with a gentle nitrogen stream, and the exchange with deuterated water was repeated 2 more times. FT-IR analysis was performed as described above, but added means were taken to reduce fiber exposure to atmospheric moisture prior to data collection.

\subsection{X-Ray Powder Diffraction}

X-ray diffraction data was collected on a Philips X-pert PW 3040 MPD X-ray powder diffractometer (Phillips Electronics, Amsterdam, the Netherlands) with $\mathrm{Cu} \mathrm{K} \alpha$ radiation. Prior to analysis cotton samples were processed through a Wiley mill using a 20 mesh screen, and pressed into a pellet. Crystallite size was calculated using the Scherrer equation [19]

$$
\tau=\mathrm{K} \cdot \lambda / \beta \cdot \cos \theta
$$

where $\tau$ signifies crystallite dimensions; $K$ is the Scherrer constant; $\beta$ is the width (in $2-\theta$ ) at half height of the peak, expressed in radians; $\lambda$ is the wavelength of the X-ray source and $\theta$ is half of the $2-\theta$ value for the position of the peak.

\section{Results and Discussion}

\subsection{ATR FT-IR Spectroscopy of the $O-H$ Stretching Region}

Vibrational spectra of MD 90ne fibers exhibit observable band changes at different developmental days. Figure 1 shows FTIR spectra of MD 90ne at 18, 20, 24, 28, 32, 36 and 40 DPA. The full mid-IR spectra, 3800-700 $\mathrm{cm}^{-1}$ for this study, can be divided into four important regions: (1) the $\mathrm{O}-\mathrm{H}$ stretching region, $3700-3000 \mathrm{~cm}^{-1}$; (2) the $\mathrm{C}-\mathrm{H}$ stretching region (not discussed), $3000-2700 \mathrm{~cm}^{-1}$; (3) the $\mathrm{O}-\mathrm{H}$ bending region, $1800-1300 \mathrm{~cm}^{-1}$; and (4) the fingerprint region with multiple $\mathrm{C}-\mathrm{O}$ vibrations, $1250-850 \mathrm{~cm}^{-1}$. A group of intense, broad $\mathrm{O}-\mathrm{H}$ stretching bands ranging from 3660 to $3000 \mathrm{~cm}^{-1}$ are observed for all samples (Figure 2a). At first inspection, the group appears to be composed of a shoulder band near $3411 \mathrm{~cm}^{-1}$ and two more prominent bands centered around 3333 and $3284 \mathrm{~cm}^{-1}$ (for the 18 DPA sample), though only the center band appears somewhat resolved. As the harvesting date increases ( $\geq 20 \mathrm{DPA}$ ), an apparent shift from $3333 \mathrm{~cm}^{-1}$ to $3330 \mathrm{~cm}^{-1}$ is observed for the dominant center band (Figure 2a). While changes in the shoulder band near $3411 \mathrm{~cm}^{-1}$ are not easily observed, the relative intensity of the broad band near $3284 \mathrm{~cm}^{-1}$, when compared to the band near $3330 \mathrm{~cm}^{-1}$, increases as the SCW increases ( $\geq 20 \mathrm{DPA})$. Also, the center of this broad band slightly shifts to $3280 \mathrm{~cm}^{-1}$ for the more developed fibers. Changes in the $\mathrm{O}-\mathrm{H}$ band can signal strengthening of the corresponding hydrogen bonds, with stronger bonds shifting the corresponding $\mathrm{O}-\mathrm{H}$ bands to lower energy. However, given the lack of resolution of these $\mathrm{O}-\mathrm{H}$ bands, it remained unclear if the observed changes arose from variations in surface $\mathrm{O}-\mathrm{H}$ groups or a more intrinsic change in the cellulose composition of the fibers.

Analysis of deuterated cotton fibers was performed to achieve a clearer picture of changes to the hydrogen bond network of cellulose fibers during cell wall development. Simple deuteration of the fibers can be used to decrease the contributions of readily accessible $\mathrm{O}-\mathrm{H}$ groups [14]. These $\mathrm{O}-\mathrm{H}$ 
groups are exchanged with $\mathrm{O}-\mathrm{D}$ groups that exhibit vibrations at lower frequencies. The remaining $\mathrm{O}-\mathrm{H}$ bands arise from the non-accessible cellulose chains and are typically better resolved, thus providing a clearer picture of the intra- and intermolecular hydrogen bonds occurring in the cellulose chains within the cotton fibers. The components of cellulose that are readily accessible to $\mathrm{D}_{2} \mathrm{O}$ exchange have been linked to the amorphous cellulose component. A second, less accessible component has also been observed and has been described as being part of semi-crystalline regions of cellulose [20,21], likely surface chains. The remaining crystalline cellulose does not exchange readily with deuterated water. After deuteration of the cotton fibers (MD 90ne at 18, 24 and 40 DPAs), broad, intense O-D bands appears centered on $2480 \mathrm{~cm}^{-1}$ for all three samples (Figure S1). As expected, the $\mathrm{O}-\mathrm{H}$ bands exhibited a significant decrease in band intensity and width (Figure 2b; a 63\% decrease in the $\mathrm{O}-\mathrm{H}$ band integration for the 18 DPA sample). The deuterated 18 DPA exhibits three $\mathrm{O}-\mathrm{H}$ bands centered at 3404, 3340 and $3289 \mathrm{~cm}^{-1}$; a slight shift to lower wavenumbers when compared to the trio of bands of the non-deutereated fiber sample $\left(3411 \mathrm{~cm}^{-1}, 3333 \mathrm{~cm}^{-1}\right.$ and $3284 \mathrm{~cm}^{-1}$ for the 18 DPA fiber). Band resolution is improved, especially for the central $\mathrm{O}-\mathrm{H}$ band. As with the non-deuterated sample, the center peak, now at $3340 \mathrm{~cm}^{-1}$, is more prominent than the two surrounding peaks. Interestingly, the $\mathrm{O}-\mathrm{H}$ stretching bands of the deuterated samples do not shift as they develop from 24 to 40 DPA. Also, the intensity of the $\mathrm{O}-\mathrm{H}$ bands uniformly increases with increasing fiber DPA. Thus, it appears that the hydrogen bonding network of non-accessible cellulose chains is maintained during SCW deposition of the examined stage (18-40 DPA).

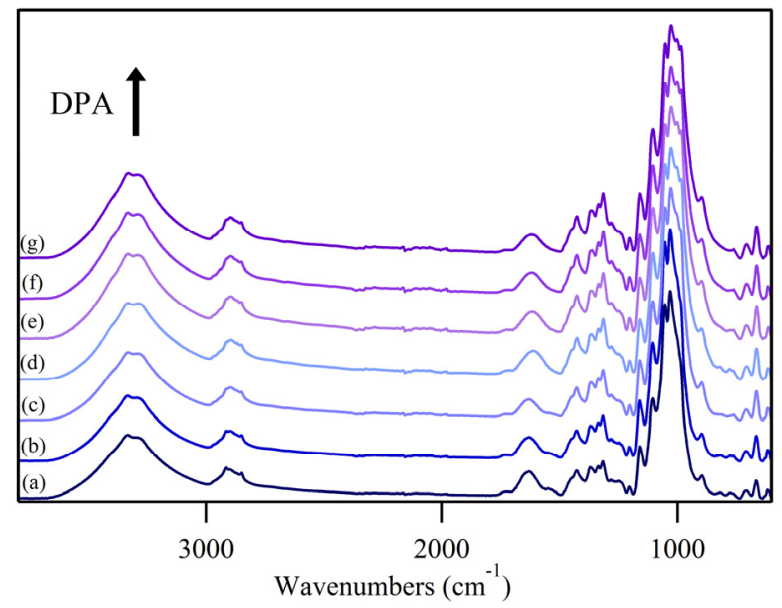

Figure 1. FTIR spectra of cotton fibers harvested at different DPA: (a) 18 days post-anthesis (DPA); (b) 20 DPA; (c) 24 DPA; (d) 28 DPA; (e) 32 DPA; (f) 36 DPA; and (g) 40 DPA. Spectra are shown shifted along the $y$-axis. 


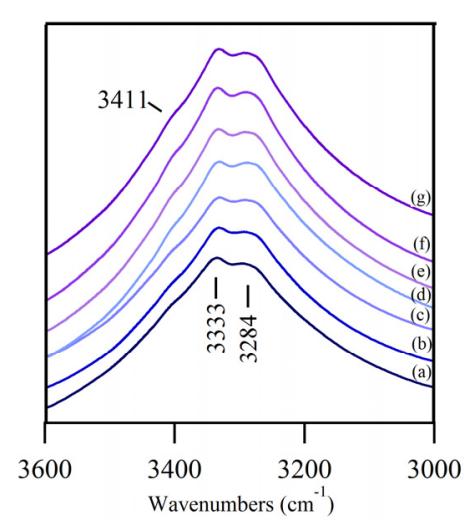

(a)

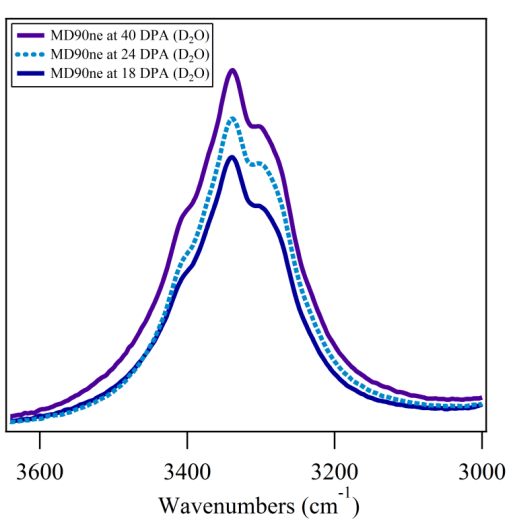

(b)

Figure 2. (a) FTIR spectra of the hydrogen-bonded $\mathrm{O}-\mathrm{H}$ stretching region for cotton fibers harvested at different DPA: (a) $18 \mathrm{DPA}$; (b) $20 \mathrm{DPA}$; (c) $24 \mathrm{DPA}$; (d) $28 \mathrm{DPA}$; (e) $32 \mathrm{DPA}$; (f) $36 \mathrm{DPA}$; and (g) $40 \mathrm{DPA}$; (b) $\mathrm{O}-\mathrm{H}$ stretching region for deuterated 18 DPA (bottom), 24 DPA (middle), and 40 DPA (top) fibers.

\section{2. $\mathrm{O}-\mathrm{H}$ Bending Region}

Previous studies have generally described intense peaks in the spectral region between 1700 and $1580 \mathrm{~cm}^{-1}$ as indicative of water absorption in cotton fibers [22]. In our samples, a wide, mid-sized band is observed. At the first three developmental stages (18-24 DPA) peaks can be observed at 1630 and $1641 \mathrm{~cm}^{-1}$ (shoulder; Figure 3a). Beginning at 28 DPA a shift to lower wavenumbers (i.e., lower energy), now centered at $1619 \mathrm{~cm}^{-1}$, and a significant broadening of the peaks is observed. Similar transitions have been previously observed [9], but the point of transition appears to be dependent on the genetic identity of the cotton fibers as well as growing conditions. To better understand the observed transitions, first derivative plots of the $\mathrm{O}-\mathrm{H}$ bending region were calculated. First derivative plots of this spectral region resolve our absorption data (Figure S2); an inflection point at $1580 \mathrm{~cm}^{-1}$ is observed for the first three developmental stages, but not for higher DPA fibers. Band shifts to a lower wavenumber would be indicative of stronger interaction of the water molecules with the hydrogen bonding network in the cellulose polymer. Treatment with deuterated water reduces band intensity and produces a decrease in band width and a significant shift to lower wavenumbers; the center of the bending located at $1611 \mathrm{~cm}^{-1}$ for the $18 \mathrm{DPA}$, and $1602 \mathrm{~cm}^{-1}$ for the 24 and 40 DPA samples (Figure 3b). We note that sample drying studies have to be performed to conclusive identify these peaks as water bands. XRD analysis reveals changes in the crystallite size of the cotton fibers during SCW development that might account for the water band changes observed (Figure 4). Calculations with the Scherrer equation indicate an increase in the cellulose crystallite size during SCW development (Figure 4, inset). We note impurities in the 20 and 28 DPA near $19^{\circ}$ that are likely decreasing the calculated crystallite values for those two samples; however, the overall crystallite size increase for the developing fibers is still clearly seen. Since the crystallite size calculation represents an average number of the crystals in the fibers, the dimensions of the crystallites in the primary cell walls are not necessarily growing in size. Instead, this number likely results from the formations of larger crystals in the SCW. The relative decrease in crystallite surface area might account for the changes observed in absorbed water interaction. 


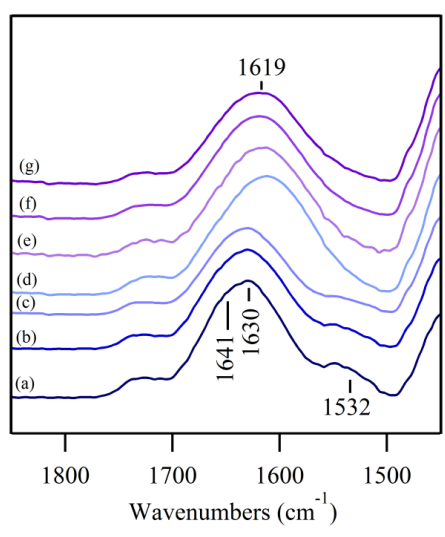

(a)

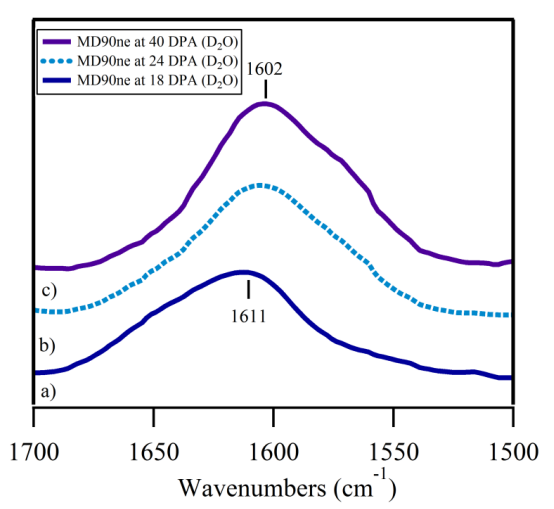

(b)

Figure 3. (a) FTIR spectra of the $\mathrm{O}-\mathrm{H}$ bending region for cotton fibers harvested at different DPA: (a) 18 DPA; (b) 20 DPA; (c) 24 DPA; (d) 28 DPA; (e) 32 DPA; (f) 36 DPA; and (g) 40 DPA; (b) O-H bending region (deuterated) harvested at 18 DPA (bottom), 24 DPA (middle), and 40 DPA (top).

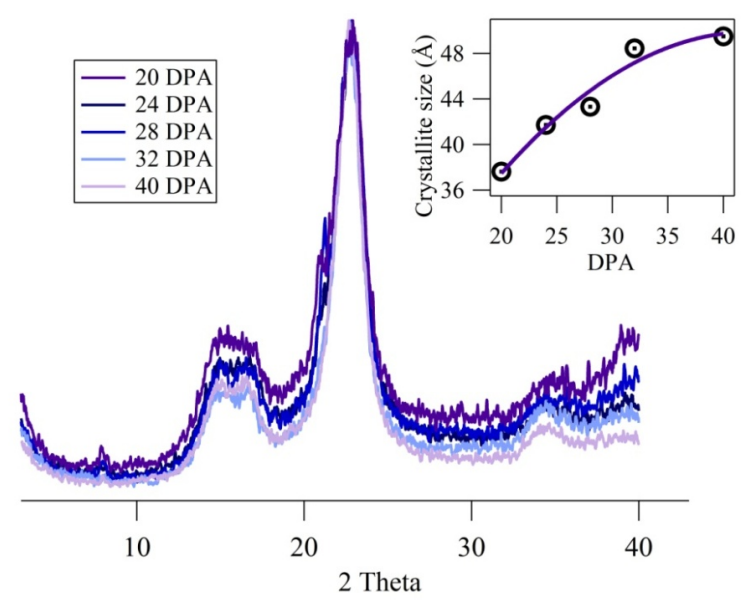

Figure 4. XRD spectra of cotton fibers harvested at different developmental time points; 20, 24, 28, 32 and 40 DPA. Inset figure shows the cellulose crystallite size as calculated by the Scherrer equation.

\subsection{Fingerprint Region; $\mathrm{C}-\mathrm{H}$ and $\mathrm{O}-\mathrm{H}$ Bending}

The collection of bands observed between 1500 and $1150 \mathrm{~cm}^{-1}$ undergoes little structural change as cotton fibers develop; only a gradual increase in band intensity is observed (Figure 5a). In the aforementioned region, a total of 9 bands are clearly observed at 1451, 1426, 1365, 1335, 1314, 1280, 1247,1203 and $1159 \mathrm{~cm}^{-1}$. The shape and positions of a number of these bands resemble reported $\mathrm{O}-\mathrm{H}$ bending bands of Valonia cellulose crystals observed at 1450,1430, 1335 and $1315 \mathrm{~cm}^{-1}$. Bands at 1365, 1275 and $1249 \mathrm{~cm}^{-1}$ were previously reported for ramie and flax fibers and described as $\mathrm{C}-\mathrm{H}$ bending modes [23], while the 1203 and $1159 \mathrm{~cm}^{-1}$ were described as symmetric and asymmetric stretching of the $\mathrm{C}-\mathrm{O}-\mathrm{C}$ glycoside. Deuteration results in decreased intensity for the $\mathrm{O}-\mathrm{H}$ bending modes. Otherwise, only minor changes in band shapes or positions are observed (Figure 5b). Only the $1451 \mathrm{~cm}^{-1}$ band shifts to $1455 \mathrm{~cm}^{-1}$, while the relatively broad band at $1365 \mathrm{~cm}^{-1}$ decreases in width 
and its peak maximum shifts to $1373 \mathrm{~cm}^{-1}$. It appears that this band forms from a combination of $\mathrm{C}-\mathrm{H}$ and $\mathrm{O}-\mathrm{H}$ modes, and that the $\mathrm{O}-\mathrm{H}$ bend is susceptible to deuteration. However, the symmetric $\mathrm{C}-\mathrm{O}-\mathrm{C}$ remains unchanged upon deuteration. Possible changes in the 1247 and $1203 \mathrm{~cm}^{-1}$ bands are obscured by the appearance of an O-D bending band at $1205 \mathrm{~cm}^{-1}$ (Figure S1).

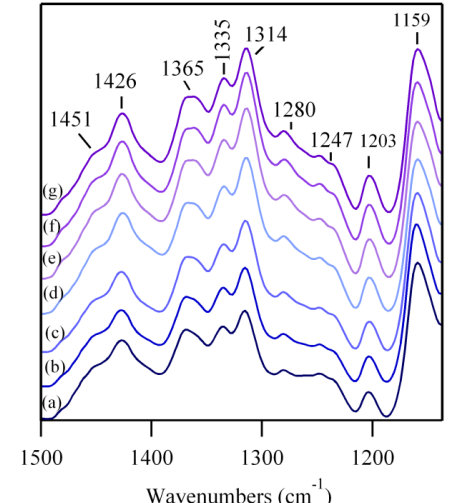

(a)

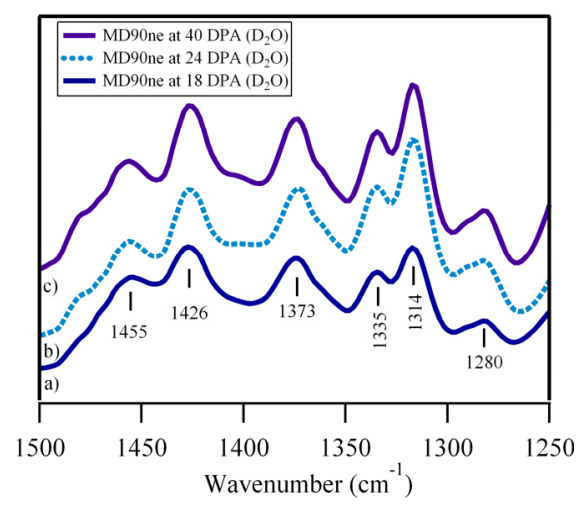

(b)

Figure 5. (a) FTIR spectra of the fingerprint region for cotton fibers harvested at different DPA: (a) 18 DPA; (b) 20 DPA; (c) 24 DPA; (d) 28 DPA; (e) 32 DPA; (f) 36 DPA; and (g) 40 DPA; (b) Spectra of the fingerprint region of cotton fibers treated with $\mathrm{D}_{2} \mathrm{O}$ and harvested at different DPA: (a) 18 DPA (bottom); (b) 24 DPA (middle); and (g) 40 DPA (top).

\subsection{Fingerprint Region; $\mathrm{C}-\mathrm{O}$ Vibrations}

Developed MD 90ne fibers exhibit 5 intense $\mathrm{C}-\mathrm{O}$ bands centered at 1104, 1052, 1028, 1002 and $985 \mathrm{~cm}^{-1}$ (Figure 6a). The first four bands correspond to reported vibrations from cellulose alcohols: $\mathrm{C}-\mathrm{O}$ vibrations of the $\mathrm{C}(2)-\mathrm{O}(2) \mathrm{H}$ secondary alcohol (reported at $1115 \mathrm{~cm}^{-1}$; observed at $1104 \mathrm{~cm}^{-1}$ for the 40 DPA sample), vibrations of the $\mathrm{C}(3)-\mathrm{O}(3) \mathrm{H}$ secondary alcohol (reported at $1060 \mathrm{~cm}^{-1}$; observed at $1052 \mathrm{~cm}^{-1}$ for the 40 DPA sample), and vibrations of primary and secondary confirmations of the $\mathrm{C}(6) \mathrm{H}_{2}-\mathrm{O}(6) \mathrm{H}$ primary alcohol (reported at 1035 and $1000 \mathrm{~cm}^{-1}$, respectively; observed at 1028 and $1002 \mathrm{~cm}^{-1}$ for the 40 DPA sample) [9,16]. While the positions for some of these bands differ from the reported values, they are susceptible to shifts depending on cell wall development. For example, the prominent $\mathrm{C}-\mathrm{O}$ band observed at $1052 \mathrm{~cm}^{-1}$ for the more developed samples, 24-40 DPA, is observed at $1055 \mathrm{~cm}^{-1}$ for the 18 and 20 DPA samples. The $\mathrm{C}(6) \mathrm{H}_{2}-\mathrm{O}(6) \mathrm{H}$ vibration observed at $1028 \mathrm{~cm}^{-1}$ in the more developed samples, 32-40 DPA, is observed at $1031 \mathrm{~cm}^{-1}$ in the 18 DPA sample, and shifts to 1030 and $1029 \mathrm{~cm}^{-1}$ as it grows to 20 and 24 DPA, respectively. In contrast, the band produced by a secondary $\mathrm{C}(6) \mathrm{H}_{2}-\mathrm{O}(6) \mathrm{H}$ vibration is observed at $1002 \mathrm{~cm}^{-1}$ starting at 24 DPA. While less developed fibers (18-24 DPA) exhibit unresolved bands near 1002 and $985 \mathrm{~cm}^{-1}$, their prominence is diminished. The fifth band we observe, centered at $985 \mathrm{~cm}^{-1}$, was not given a band assignment by Marechal and Chanzy; however, in their study a small shoulder band is observed near $982 \mathrm{~cm}^{-1}$ [16]. They described several bands near this region $\left(989 \mathrm{~cm}^{-1}\right)$ as $\mathrm{C}-\mathrm{O}$ bending vibrations from alcohols involved in weak hydrogen bonding, likely from surface cellulose chains of the Valonia crystals [16]. Liu and coworkers [11] also described bands in the region $\left(956-1050 \mathrm{~cm}^{-1}\right)$ as $\mathrm{C}-\mathrm{O}$ vibrational peaks from cellulosic alcohols in the cotton fibers. The intensity of the $985 \mathrm{~cm}^{-1}$ band in 
our samples increased with fiber DPA, and slightly shifted from $987 \mathrm{~cm}^{-1}$ in the 24 DPA sample to $985 \mathrm{~cm}^{-1}$ in samples at higher developmental points (28-40 DPA). This intensity trend was previously described and used to estimate the maturity ratio of cotton fibers [11].

Figure 6b shows FT-IR spectra of MD 90ne at 18 and 40 DPA that have been baseline-corrected, normalized, and are presented without a shift in the absorbance axis; the figure better displays the decreased intensity of the peaks 1002 and $985 \mathrm{~cm}^{-1}$ for the underdeveloped fiber (18 DPA). Fiber deuteration produces slight shifts in three of the more energetic $\mathrm{C}-\mathrm{O}$ bands which are then observed at 1111,1055 and $1031 \mathrm{~cm}^{-1}$. The bands at 1002 and $985 \mathrm{~cm}^{-1}$; however, do not undergo a significant shift.

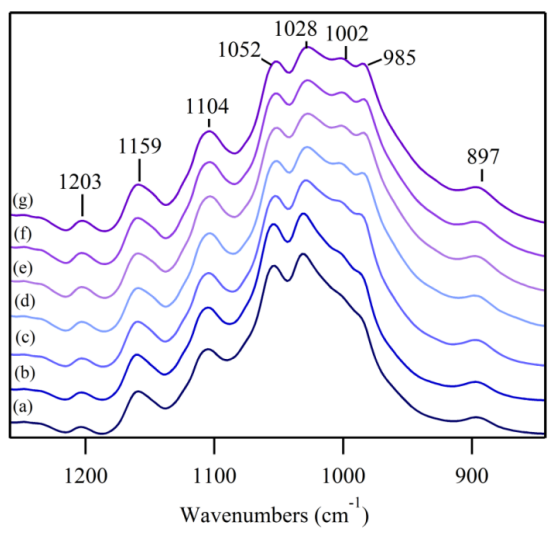

(a)

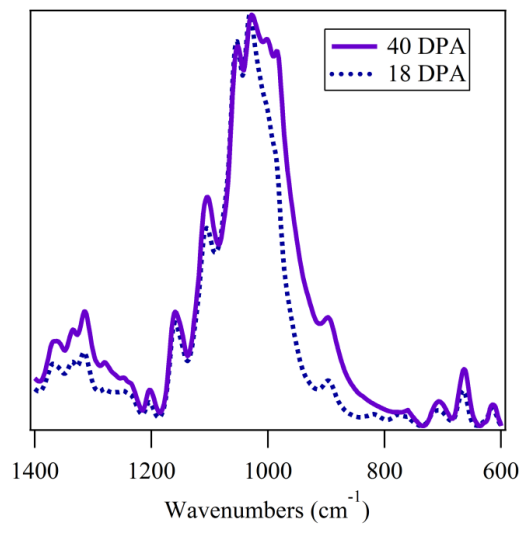

(b)

Figure 6. (a) FTIR spectra of the $\mathrm{C}-\mathrm{O}$ stretching region for cotton fibers harvested at different DPA: (a) 18 DPA; (b) 20 DPA; (c) 24 DPA; (d) 28 DPA; (e) 32 DPA; (f) 36 DPA; and (g) 40 DPA; (b) spectra for fibers harvested at 18 DPA and 40 DPA, shown without a y-axis shift.

\section{Conclusions}

Cotton cell wall development was examined with ATR FT-IR spectroscopy paying particular attention to changes in the hydrogen bonding network of cellulose. ATR FT-IR spectra of deuterated cotton fibers indicate little change in the band shape and positions for cellulose $\mathrm{O}-\mathrm{H}$ stretching bands as the cotton fibers develops secondary wall. Only a progressive increase in $\mathrm{O}-\mathrm{H}$ band intensity is observed. Thus, the deposition of highly crystalline cellulose during secondary cell wall formation does not significantly alter the hydrogen bond network of highly crystalline cellulose. A number of notable spectral changes were observed during development, which is in accordance with previous reports [9,11]. Most notably, there is a marked intensity increase for the $\mathrm{C}-\mathrm{O}$ vibrations at 1002 and $985 \mathrm{~cm}^{-1}$.

\section{Supplementary Materials}

Supplementary materials can be accessed at: http://www.mdpi.com/2079-6439/3/1/30/s1.

\section{Acknowledgments}

The authors thank Jeannine Moraitis and Clare Kappel of SRRC-ARS-USDA for their outstanding work in performing the analyses, and Chanel Fortier, Aaron Smith and Katherine Freeman for their 
suggestions on the manuscript. Partial funding for this research project was provided by Cotton Incorporated.

\section{Author Contributions}

Michael Santiago Cintrón conceived the research, organized and performed FT-IR experiments, interpreted the results, and wrote the manuscript. Doug J. Hinchliffe conceived the research, cultivated the cotton samples, and wrote portions of the manuscript.

\section{Conflicts of Interest}

The authors declare no conflict of interest.

\section{References}

1. Wakelyn, P.J.; Bertoniere, N.R.; French, A.D.; Thibodeaux, D.P.; Triplett, B.A.; Rouselle, M.A.; Goynes, W.R.; Edwards, J.V.; Hunter, L.; McAllister, D.D.; et al. Cotton Fiber Chemistry and Technology; CRC Press: New York, NY, USA, 2007.

2. Tripp, V.W.; Moore, A.T.; Rollins, M.L. Some observations on the constitution of the primary wall of the cotton fiber. Text. Res. J. 1951, 21, 886-894.

3. Tripp, V.W.; Rollins, M.L. Morphology and chemical composition of certain components of cotton fiber cell wall. Anal. Chem. 1952, 24, 1721-1728.

4. Kim, H.J.; Triplett, B.A. Cotton fiber growth in planta and in vitro. Models for plant cell elongation and cell wall biogenesis. Plant Physiol. 2001, 127, 1361-1366.

5. Seagull, R.W.; Oliveri, V.; Murphy, K.; Binder, A.; Kothari, S. Cotton fiber growth and development 2. Changes in cell diameter and wall birefringence. J. Cotton Sci. 2000, 4, 97-104.

6. Cosgrove, D.J. Growth of the plant cell wall. Nat. Rev. Mol. Cell Biol. 2005, 6, 850-861.

7. Gamble, G.R. Variation in surface chemical constituents of cotton (Gossypium hirsutum) fiber as a function of maturity. J. Agric. Food Chem. 2003, 51, 7995-7998.

8. Gilbert, M.K.; Turley, R.B.; Kim, H.J.; Li, P.; Thyssen, G.; Tang, Y.; Delhom, C.D.; Naoumkina, M.; Fang, D.D. Transcript profiling by microarray and marker analysis of the short cotton (Gossypium hirsutum L.) fiber mutant Ligon lintless-1 (Li $\left.i_{1}\right)$. BMC Genomics 2013, 14, 403.

9. Abidi, N.; Hequet, E.; Cabrales, L.; Gannaway, J.; Wilkins, T.; Wells, L.W. Evaluating cell wall structure and composition of developing cotton fibers using Fourier transform infrared spectroscopy and thermogravimetric analysis. J. Appl. Polym. Sci. 2008, 107, 476-486.

10. Abidi, N.; Cabrales, L.; Hequet, E. Fourier transform infrared spectroscopic approach to the study of the secondary cell wall development in cotton fiber. Cellulose 2010, 17, 309-320.

11. Liu, Y.; Thibodeaux, D.; Gamble, G. Development of Fourier transform infrared spectroscopy in direct, non-destructive, and rapid determination of cotton fiber maturity. Text. Res. J. 2011, 81, $1559-1567$.

12. Abidi, N.; Hequet, E.; Cabrales, L. Applications of Fourier Transform Infrared Spectroscopy to study cotton fibers. In Fourier Transforms-New Analytical Approaches and FTIR Strategies; Nikolic, G., Ed.; InTech: Cairo, Egypt, 2011. pp. 89-114 
13. Nelson, M.L.; Mares, T. Accessibility and lateral order distribution of cellulose in the developing cotton fiber. Text. Res. J. 1965, 35, 592-603.

14. Lokhande, H.T.; Daruwalla, E.H.; Padhye, M.R. Deuteration of cotton fibers. II. A novel method of deuteration-infrared study of cellulose in fiber form. J. Appl. Polym. Sci. 1977, 21, 2943-2952.

15. Hinchliffe, D.J.; Yeater, K.M.; Kim, H.J.; Woodward, A.W.; Chen, Z.J.; Meredith, W.R.; Triplett, B.A. Near-isogenic cotton germplasm lines that differ in fiber-bundle strength have temporal differences in fiber gene expression patterns as revealed by comparative high-throughput profiling. Theor. Appl. Genet. 2010, 120, 1347-1366.

16. Maréchal, Y.; Chanzy, H. The hydrogen bond network in $\mathrm{I}_{\beta}$ cellulose as observed by infrared spectrometry. J. Mol. Struct. 2000, 523, 183-196.

17. Meredith, W.R. Minimum number of genes controlling cotton fiber strength in a backcross population. Crop Sci. 2005, 45, 1114-1119.

18. Meredith, W.R. Registration of MD 52ne high fiber quality cotton germplasm and recurrent parent MD 90ne. Crop Sci. 2005, 45, 807-808.

19. Scherrer, P. Bestimmung der Grösse und der inneren Struktur von Kolloidteilchen mittels Röntgenstrahlen. Nachr. Ges. Wiss. Göttingen 1918, 26, 98-100. (In German)

20. Jeffries, R. The amorphous fraction of cellulose and its relation to moisture sorption. J. Appl. Polym. Sci. 1964, 8, 1213-1220.

21. Rousselle, M.A.; Nelson, M.L. Accessibility of cotton cellulose by deuterium exchange. Text. Res. J. 1971, 41, 599-604.

22. Fan, Q.G.; Lewis, D.M.; Tapley, K.N. Characterization of cellulose aldehyde using fourier transform infrared spectroscopy. J. Appl. Polym. Sci. 2001, 82, 1195-1202.

23. Tsuboi, M. Infrared spectrum and crystal structure of cellulose. J. Polym. Sci. 1957, 25, 159-171.

(C) 2015 by the authors; licensee MDPI, Basel, Switzerland. This article is an open access article distributed under the terms and conditions of the Creative Commons Attribution license (http://creativecommons.org/licenses/by/4.0/). 